\title{
ACORDO SOBRE BIODIVERSIDADE MARINHA PARA ALÉM DA JURISDIÇÃO NACIONAL (BBNJ): REGIME JURÍDICO INTERNACIONAL DE UTILIZAÇÃO SUSTENTÁVEL DOS RECURSOS GENÉTICOS MARINHOS DO ALTO MAR E DA ÁREA
}

\author{
André de Paiva Toledo ${ }^{1}$ \\ \begin{tabular}{l|l|}
\hline Escola Superior Dom Helder Câmara (ESDHC) &
\end{tabular}
}

Kiwonghi Bizawu²

Escola Superior Dom Helder Câmara (ESDHC)

\section{RESUMO}

A Organização das Nações Unidas participa da construção do sistema jurídico marinho. Em sua terceira conferência sobre o direito do mar, adotou-se a Convenção das Nações Unidas sobre o direito do mar (CNUDM), que, tendo dispositivos relacionados com a biodiversidade marinha, não trata expressamente dos recursos genéticos. Diante disso, as Nações Unidas convocaram uma conferência de negociação de um Acordo sobre conservação e utilização sustentável da biodiversidade marinha para além da jurisdição nacional (BBNJ), que se iniciou em 2018. Partindo da análise de dispositivos da CNUDM, que veda a modificação do princípio da liberdade no alto mar e o princípio do patrimônio comum da humanidade na Área, pretende-se propor um modelo de regime jurídico de utilização sustentável da BBNJ a ser adotado ao fim das atuais negociações. Concluise que, em razão do disposto na CNUDM, não é possível que os recursos genéticos marinhos para além da jurisdição nacional sejam uniformemente regidos no Acordo. Por conseguinte, os recursos genéticos do alto mar deveriam ser transformados de res nullius em res communis, enquanto

1 Doutor em Direito pela Université Panthéon - Assas Paris 2. Mestre e bacharel em Direito pela Universidade Federal de Minas Gerais (UFMG). Professor do Programa de Pós-Graduação em Direito da ESDHC. ORCID: https://orcid.org/0000-0002-9258-0027 / e-mail: depaivatoledo@gmail.com

2 Pós-Doutor pela Universidade de Coimbra (UC). Doutor e mestre em Direito pela Pontifícia Universidade Católica de Minas Gerais (PUC - MINAS). Especialista em Direito do Trabalho e Previdenciário pela Universidade Estácio de Sá (UES). Graduado em Direito pela Faculdade de Ciências Jurídicas e Sociais Vianna Júnior (FCJSVJ). ORCID: https://orcid.org/0000-0003-28143639/e-mail: sebak_07@hotmail.com 
aqueles encontrados na Área, por já serem res communis humanitatis, deveriam submetidos à gestão da Autoridade Internacional dos Fundos Marinhos.

Palavras-chave: alto mar; área; $\mathrm{BBNJ}$; recursos genéticos marinhos; utilização sustentável.

\section{AGREEMENT ON MARINE BIODIVERSITY BEYOND NATIONAL JURISDICTION (BBNJ): INTERNATIONAL LEGAL REGIME FOR THE SUSTAINABLE USE OF MARINE GENETIC RESOURCES IN THE HIGH SEAS AND THE AREA}

\section{ABSTRACT}

The United Nations participates in the construction of the marine legal system. At its third conference on the Law of the Sea, the United Nations Convention on the Law of the Sea (UNCLOS) was adopted, which, having provisions related to biodiversity, does not expressly address genetic resources. In view of this, the United Nations convened a conference to negotiate an Agreement on the conservation and sustainable use of marine biodiversity beyond the national jurisdiction (BBNJ), which began in 2018. Based on the analysis of the UNCLOS provisions, which prohibit the modification of the principle of freedom in the high seas and the principle of the common heritage of mankind in the Area, it is intended to propose a model of legal regime for the sustainable use of $B B N J$ to be adopted at the end of the current negotiations. Due to the provisions of UNCLOS, it is not possible for marine genetic resources beyond national jurisdiction to be uniformly ruled in the Agreement. Consequently, the genetic resources of the high seas should be transformed from res nullius into res communis, while those found in the Area, since they are already res communis humanitatis, should be submitted to the management of the International Seabed Authority.

Keywords: area; BBNJ; high seas; marine genetic resources; sustainable use. 


\section{INTRODUÇÃO}

Derrotado o nazifascismo. Estados integrantes da sociedade internacional reuniu-se para dar início a uma nova ordem internacional, fundada nos princípios da boa-fé, transparência, cooperação e solução pacífica de controvérsias, a fim de, enfim, formar uma comunidade internacional para a realização da paz, garantia da segurança e proteção da dignidade humana. Encerrada a "Segunda Guerra dos Trinta Anos"3 (LOSURDO, 2017, p. 266), os Estados buscavam aprofundar as bases de uma liga das nações, tornando-a mais solidária por ação de nações unidas.

Em (re)construção da ordem jurídica internacional, ainda em 1945, constituiu-se a Organização das Nações Unidas (doravante "Nações Unidas"), que, de pronto, configurou-se simultaneamente como sujeito protagonista e foro privilegiado de negociações entre Estados. A importância do papel das Nações Unidas na consagração de uma nova ordem internacional global tem sido demonstrada por uma contínua e significativa produção normativa. Pouco depois do início de suas atividades, em 1948, por meio da Resolução 217(III) de sua Assembleia Geral, adotou-se a Declaração Universal de Direitos Humanos, que foi concebida para ser instrumento basilar do sistema internacional de proteção dos direitos humanos. A partir de então, desenvolveu-se paulatinamente um sistema mais amplo de proteção internacional da dignidade humana (O'REGAN, 2018), que foi elevada à categoria teleo-axiológica da ordem internacional pós-positivista,

Nas últimas décadas, as Nações Unidas têm se destacado não apenas no fortalecimento dos direitos humanos, mas no desenvolvimento de outras dimensões normativas. Em razão de sua ampla finalidade e do grande número de membros, a organização internacional tem tido legitimidade suficiente para fazer avançar diversas negociações sobre o direito ao desenvolvimento socioeconômico e sobre a obrigação de proteção do meio ambiente.

Em um contexto de descolonização e consolidação da autodeterminação dos povos, as Nações Unidas participaram diretamente da identificação do princípio da soberania nacional sobre os recursos naturais em uma perspectiva de superação do subdesenvolvimento das ex-colônias (TYAGI, 2015). A construção de um sistema jurídico de segunda dimensão se

3 A Segunda Guerra dos Trinta Anos corresponde ao período de 1914 a 1945, quando ocorreram os dois conflitos armados mundiais. Trata-se de uma expressão usada por historiadores em referência à [Primeira] Guerra dos Trinta Anos, ocorrida entre 1618 e 1648, que, a partir da celebração dos Tratados de Vestfália, consagrou uma nova ordem internacional europeia (DAILLIER; FORTEAU; PELLET, 2009, p. 61). 
deu como desdobramento da Declaração sobre a concessão de independência aos países e povos coloniais, adotada em 1960 por meio da Resolução 1514 (XV) da Assembleia Geral.

No que concerne à dimensão ambientalista, o objetivo de cada Estado de alcançar os níveis adequados de desenvolvimento econômico teve que se adaptar às urgências ecológicas. De acordo com a noção de desenvolvimento sustentável, consolidada em 1987 com a publicação do Relatório Brundtland $^{4}$, a atividade econômica nacional passa a ser entendida como lícita, quando atendidos os requisitos internacionais de sustentabilidade. Os resultados das conferências de Estocolmo (1972) e Rio de Janeiro (1992), realizadas ambas sob os auspícios das Nações Unidas, são evidências da importância dessa organização para a vigência de um sistema jurídico internacional tridimensional, constituído por direitos individuais, sociais e ambientais (SOARES, 2001).

Fiadoras da nova ordem internacional, as Nações Unidas participam também da reorganização do sistema jurídico marinho. Estando em vigor normas esparsas de natureza consuetudinária e convencional sobre a gestão e conservação do oceano, a organização internacional decidiu convocar seus membros para uma conferência de codificação do costume marinho e criação de novos regimes jurídico-marinhos ${ }^{5}$. O propósito último da reunião, que se realizou em Genebra, em 1958, consistia em adequar o direito do mar aos novos desafios da comunidade internacional.

Com relação a essa primeira conferência, destaca-se o fato de, bem antes da conferência de Estocolmo sobre meio ambiente humano, celebrar-se, no âmbito das Nações Unidas, um instrumento jurídico vinculante dedicado exclusivamente à preservação dos recursos biológicos do alto mar, o que tem relação direta com o objeto deste trabalho. $\mathrm{O}$ fato de ter sido adotada em 1958 a Convenção sobre pesca e conservação dos recursos vivos do alto mar demonstra que o direito do mar, há bastante tempo, não se restringe a temas sobre a navegação, mas dedica-se especialmente à utilização sustentável dos recursos naturais marinhos.

Fracassada a segunda conferência das Nações Unidas sobre direito do mar, realizada em 1960, em Genebra, quando não se conseguiu uniformizar as temáticas jurídicas marinhas em um único tratado internacional

4 Esse relatório, intitulado Nosso futuro comum, foi elaborado pela Comissão Mundial sobre Meio Ambiente e Desenvolvimento das Nações Unidas, presidida por Gro Harlem Brundtland.

5 As convenções das Nações Unidas sobre o direito do mar, celebradas em Genebra, em 1958, além de codificarem os costumes então vigentes, estabeleceram novos regimes jurídico-marinhos, quais sejam o regime da zona contígua e o regime da plataforma continental (YANAI, 2012). 
(BEURIER, 2014c), foi necessário aguardar alguns anos para que a organização internacional convocasse sua terceira conferência, iniciada em 1973. Após anos de surpreendentes negociações (LEVY, 1980), adotou-se, em 1982, em Montego Bay, a Convenção das Nações Unidas sobre Direito do Mar (doravante "CNUDM"), em vigor desde 1994. Com mais de 160 partes, inclusive a União Europeia, a CNUDM tornou-se a base do direito do mar contemporâneo, sendo chamada por alguns doutrinadores, em virtude de sua importância, de "Constituição dos mares" (ZANELLA, 2017, p. 82). Entre os diversos temas inseridos na CNUDM, encontram-se evidentemente dispositivos sobre a utilização sustentável dos recursos biológicos marinhos, tendo em vista que as negociações desse tratado internacional foram influenciadas pela adoção, no ano anterior, da Declaração de Estocolmo sobre Meio Ambiente Humano (ADEDE, 1995).

Acerca do tema do uso da biodiversidade marinha, é possível identificar dois eixos grandes normativos: o direito de pesca e o direito sobre "outras utilizações legítimas" dos recursos biológicos do mar. Entre estas, destacam-se as vinculadas ao trabalho biotecnológico com base nos conhecimentos de engenharia genética. Diante do recente e vigoroso desenvolvimento do setor biotecnológico, o acesso aos recursos genéticos marinhos e sua preservação tornaram-se questões estratégicas para todos os Estados e passaram a compor a pauta de diversas negociações internacionais (LEARY et al., 2009, p. 183).

Mais recentemente, constatada a insuficiência da CNUDM para solucionar as controvérsias internacionais sobre a utilização sustentável dos recursos genéticos marinhos, a Assembleia Geral das Nações Unidas, em 24 de dezembro de 2017, adotou a Resolução 72/249, por meio da qual convocou seus membros para negociar um novo tratado internacional juridicamente vinculante, sob a égide da CNUDM, sobre a conservação e uso sustentável da diversidade biológica marinha fora da jurisdição nacional (doravante "BBNJ", na sigla inglesa). As negociações se iniciaram em 2018 e, por causa da pandemia de COVID-19, devem ser concluídas em $2021^{7}$.

Tendo como base o disposto na referida resolução, um futuro Acordo 6 Art. $1^{\circ}, 1,4$, da CNUDM.

7 Em carta redigida em inglês e remetida, em 10 de setembro de 2020, aos representantes permanentes dos Estados membros, aos membros das agências especializadas e às partes da CNUDM, a presidente da conferência das Nações Unidas sobre BBNJ, a embaixatriz Rena Lee, informa que a quarta e - a princípio - última sessão das negociações acontecerá em 2021. Disponível em https://www.un.org/ bbnj/sites/www.un.org.bbnj/files/intersessional_work_-_bbnj_president_letter_to_delegations.pdf. Acesso em: 23 set. 2020. 
sobre BBNJ somente pode ser adotado em conformidade com os limites jurídicos vigentes na CNUDM. Após a realização de três sessões da conferência sobre BBNJ, em 2018 e 2019, e a redação do esboço do texto do Acordo $^{8}$, o presente artigo constata a impossibilidade de instituição de um regime jurídico único para os recursos genéticos do alto mar e da Área, indicando, em seguida, uma solução sistemicamente mais adequada ao problema do regime jurídico internacional de utilização sustentável da BBNJ.

Para tanto, analisam-se os dispositivos da CNUDM de limitação às negociações do Acordo sobre BBNJ, em comparação com dispositivos do Acordo de 1995 para implementação da CNUDM sobre a conservação e gestão de estoques de peixes transzonais e altamente migratórios e dispositivos do sistema jurídico internacional antártico.

\section{LIMITES DA CNUDM PARA O ACORDO SOBRE BBNJ}

Todos os Estados têm soberania para negociar livremente com outros sujeitos de direito internacional instrumentos obrigacionais. Contudo, a soberania para a criação de normas deve ser exercida em conformidade com o próprio direito internacional. A liberdade negocial dos Estados está condicionada ao respeito dos limites vigentes na própria ordem jurídica. De fato, a forma e o conteúdo de um novo dispositivo jurídico internacional não podem estar em desacordo com o sistema jurídico internacional geral, que lhe garante validade. Basta lembrar que a Seção 2 da Parte V da Convenção de Viena sobre o direito dos tratados, celebrada em 1969, trata justamente da nulidade dos tratados internacionais em conflito com o direito internacional em vigor. Logo, antes mesmo do início das tratativas, em conferência, os Estados não têm liberdade absoluta para inovar, pois o sistema jurídico como um todo pretende-se coerente.

No que concerne às negociações do Acordo sobre BBNJ, em curso desde 2018, ficou definido, na Resolução 72/249 da Assembleia Geral das Nações Unidas, que tal instrumento deve ser adotado sob a égide da CNUDM $^{9}$. Logo, essa convenção é um necessário parâmetro para

\footnotetext{
8 Revised draft text of an agreement under the United Nations Convention on the Law of the Sea on the conservation and sustainable use of marine biological diversity of areas beyond national jurisdiction, produzido pelas Nações Unidas em 27 de novembro de 2019 e disponível em https://www.un.org/bbnj/ sites/www.un.org.bbnj/files/revised_draft_text_a.conf_.232.2020.11_advance_unedited_version.pdf.

9 Não seria a primeira vez que isso acontece. Em 1994 e 1995, houve a adoção de dois acordos para a implementação da CNUDM: respectivamente, o Acordo sobre a Parte XI e o Acordo sobre conservação e gestão dos estoques de peixes transzonais e altamente migratórios, cujos dispositivos convencionais encontram-se na Parte $\mathrm{V}$ dedicada à zona econômica exclusiva. O Acordo sobre BBNJ seria, portanto, a terceira experiência das Nações Unidas de adoção de um tratado de implementação da CNUDM.
} 
a construção do consenso em torno do Acordo sobre BBNJ. Por isso, o futuro Acordo sobre BBNJ, uma vez adotado, deve estar necessariamente em consonância com o sistema jurídico fixado em Montego Bay, em 1982.

Para compreender o horizonte de negociações sobre BBNJ, deve-se buscar no texto da CNUDM os dispositivos que tratam da possibilidade de emenda, suspensão e revogação de seu texto. De pronto, destaca-se o art. 311,3 , que estabelece que:

\footnotetext{
Dois ou mais Estados Partes podem concluir acordos, aplicáveis unicamente às suas relações entre si, que modifiquem as disposições da presente Convenção ou suspendam a sua aplicação, desde que tais acordos não se relacionem com nenhuma disposição cuja derrogação seja incompatível com a realização efetiva do objeto e fins da presente Convenção e, desde que tais acordos não afetem a aplicação dos princípios fundamentais nela enunciados e que as disposições de tais acordos não afetem o gozo por outro Estados Partes dos seus direitos ou o cumprimento das suas obrigações nos termos da mesma Convenção (BRASIL, 1990).
}

Diante disso, o futuro Acordo sobre BBNJ não pode implicar uma derrogação incompatível com a finalidade e objetivo da CNUDM nem afetar a aplicação dos princípios fundamentais nela enunciados. No que concerne à temática sobre $\mathrm{BBNJ}$, quais princípios deveriam ser identificados como limites para a validade do Acordo? Para responder, é necessário conhecer o objeto de negociação. De imediato, verifica-se que se trata de um projeto de tratado sobre conservação e utilização sustentável da diversidade biológica marinha, que se encontra naturalmente para além dos espaços de jurisdição nacional.

No que concerne à biodiversidade, mesmo não havendo menção expressa a esse termo em todo o texto da CNUDM, seu objeto está ali previsto. Com efeito, apesar de não se referir ao significante biodiversidade ou diversidade biológica, tendo por base o disposto no art. $2^{\circ}$ da Convenção sobre diversidade biológica, também celebrada sob os auspícios das Nações Unidas, em 1992, que define biodiversidade como a variabilidade de organismos vivos, compreendendo os ecossistemas marinhos, os complexos ecológicos, a diversidade dentro de espécies, entre espécies e de ecossistemas, a CNUDM dispõe sobre o significado biodiversidade quando se refere a "recursos vivos"10, "vida marinha"11, "organismos vivos"12

10 Preâmbulo e arts. $1,1,4,21,1, d, 56,1, a, 61,62,69,70,71,73,1,117,118,119,123, a, 246,5, a$, 277, $a, 297,3, a, 297,3, b, \mathrm{i}, 297,3, b$, ii, da CNUDM.

11 Arts. 1, 1, 4, 194, 5, da CNUDM.

12 Art. 77, 4, da CNUDM.

Veredas do Direito, Belo Horizonte, ·v.17 · n.39 · p.339-366 · Setembro/Dezembro de 2020 
e "espécies" normas sobre a diversidade biológica marinha, "incluindo a pesca e as outras utilizações legítimas do mar"14, o que inclui a pesquisa científica e a utilização dos recursos genéticos marinhos.

Em uma primeira análise, ao tratar da biodiversidade marinha, compõem esse conjunto os recursos pesqueiros e os recursos genéticos. Apesar de a atividade pesqueira ser expressamente mencionada em diversos artigos da CNUDM, não há qualquer definição para recurso pesqueiro. Isso não impede, entretanto, que diversas definições sejam encontradas em instrumentos jurídicos internacionais de cooperação em matéria de pesca, que têm sido celebrados em conformidade com a CNUDM. De todo modo, apesar das dificuldades terminológicas ${ }^{15}$, pode-se identificar a diferenciação entre peixe como mercadoria (recurso pesqueiro) e peixe valorizado por suas propriedades genéticas (recurso genético) (LEARY, 2019). Logo, quando a captura do recurso vivo tem por finalidade sua inserção na cadeia produtiva alimentar ${ }^{16}$, tal atividade deve ser trata como pescaria. Caso a captura tenha a finalidade de inserção do recurso vivo na dinâmica produtiva típica da engenharia biomolecular ${ }^{17}$, está-se diante de recursos genéticos.

Em virtude da diferença terminológica entre recursos pesqueiros e recursos genéticos marinhos e reconhecendo a importância do direito internacional de pescas em vigor, as negociações do Acordo sobre BBNJ têm expressamente afastado a temática sobre pesca, restringindo-se à utilização dos recursos genéticos marinhos ${ }^{18}$. Logo, apesar de ser uma conferência sobre diversidade biológica, seu objeto tende a se concentrar em sua dimensão genética.

De acordo com a CNUDM, os espaços de jurisdição nacional mais periféricos são a plataforma continental e a zona econômica exclusiva. Os

13 Arts. 61-64, 67, 68, 77, 4, 119, 194, 5, 196, Anexo I da CNUDM.

14 Art. 1, 1, 4, da CNUDM.

15 Apesar de reconhecer o problema terminológico, não é objetivo da presente pesquisa tratar da diferenciação conceitual entre recursos pesqueiros e recursos genéticos marinhos.

16 Com a consagração da nova ordem internacional global, após o fim da Segunda Guerra Mundial, o número de comissões internacionais de pesca aumenta rapidamente em razão dos esforços da Organização das Nações Unidas para a Alimentação e a Agricultura (BEURIER, 2014a, p. 1319).

17 O desenvolvimento da engenharia biomolecular tem possibilitado a utilização da diversidade biológica marinha não apenas para o descobrimento de organismos transgênicos, mas sobretudo para a produção industrial de cosméticos e medicamentos (BEURIER, 2014b, p. 1349).

18 Art. 8, 2, a, de Revised draft text of an agreement under the United Nations Convention on the Law of the Sea on the conservation and sustainable use of marine biological diversity of areas beyond national jurisdiction. 
espaços fora da jurisdição são aqueles que se encontram fora desses dois espaços de jurisdição nacional, quais sejam, respectivamente, a Área e o alto mar. Mesmo no caso do Oceano Austral, isto é, o espaço marinho localizado ao sul de 60 graus de latitude sul, o Tratado da Antártida, celebrado em Washington, em 1959, determina, em seu art. VI, que seus dispositivos não prejudicam os direitos ou o exercício dos direitos de qualquer Estado, de acordo com o direito internacional aplicável ao alto mar, no interior daquele espaço antártico. De todo modo, de acordo com a CNUDM, há apenas dois espaços marinhos fora da jurisdição nacional: alto mar e Área. O futuro Acordo sobre BBNJ deve, portanto, se restringir a utilização dos recursos genéticos desses dois espaços jurídico-marinhos.

\section{RECURSOS GENÉTICO MARINHOS DO ALTO MAR: "RES NULLIUS"}

No que concerne ao alto mar, o art. 86 da CNUDM determina que são "todas as partes do mar não incluídas na zona econômica exclusiva, no mar territorial ou nas águas interiores de um Estado, nem nas águas arquipelágicas de um Estado arquipélago”. Logo, o Acordo sobre BBNJ pretende regular a utilização dos recursos genéticos que se encontram naturalmente na coluna d'água para além das águas nacionais do Estado costeiro.

A internacionalização do alto mar é reconhecida no art. 89 da CNUDM, que estabelece que "nenhum Estado pode legitimamente pretender submeter qualquer parte do alto mar à sua soberania". Esse artigo, que trata da ilegitimidade do exercício de soberania ou direitos soberanos naquele espaço pelos Estados, garante sua internacionalização e permite a conclusão de que o alto mar é um espaço marítimo fora da jurisdição nacional.

O princípio da liberdade do alto mar está consolidado na ordem jurídica internacional desde o século XIX (CHURCHILL; LOWE, 1999), devendo ser consequentemente tratado como princípio fundamental da CNUDM, nos termos de seu art. 311, 3. A liberdade do alto mar significa não apenas a impossibilidade de territorialização pelos Estados, mas também a liberdade de prática de atividades (TANAKA, 2015), o que tem relação direta com a utilização dos recursos genéticos marinhos.

Visto isso, com relação à apropriação dos recursos naturais do alto mar, deve-se recorrer ao art. 87 da CNUDM, que prevê expressamente a liberdade do alto mar. Esta compreende, entre outras, para os Estados costeiros e sem-litoral as seguintes liberdades: navegação, sobrevoo, 
instalação de cabos e dutos submarinos, construção de ilhas artificiais e outras instalações, pesca e pesquisa científica. Especificamente sobre a biodiversidade marinha, há duas espécies de liberdade que se destacam: a liberdade de pesca $^{19}$ e a liberdade de pesquisa científica ${ }^{20}$.

Ao exercer esses direitos de liberdade, todos os Estados podem fazê-lo sem ter obrigações de contrapartida em benefício da comunidade internacional. Na CNUDM, não há previsão de retribuição pela exploração, aproveitamento e pesquisa com recursos biológicos do alto mar. Há, portanto, a livre e gratuita apropriação da biodiversidade marinha encontrada ali naturalmente pelos nacionais dos Estados da bandeira. Uma vez capturado, coletado ou acessado o recurso biológico do alto mar, o Estado da bandeira da embarcação nada deve à comunidade internacional, o que permite a conclusão de que esses recursos biológicos são internacionalmente res nullius (TOLEDO, 2019), isto é, recursos apropriáveis por quem primeiro alcança (LE HARDY, 2002, p. 40), sejam eles pesqueiros ou genéticos (BEURIER, 2014b).

$\mathrm{O}$ alto mar se encontra aberto a todos os Estados - mesmo aqueles cujo território terrestre não tem saída para o mar - e que a liberdade do alto mar deve ser exercida de acordo com o previsto na CNUDM e "nas demais normas de direito internacional" 21 . Ao abrir a possibilidade de outros tratados internacionais disporem sobre a utilização do alto mar, conclui-se que as partes da CNUDM podem acordar diferentes condições jurídicas para a realização da pesca, pesquisa científica ou utilização dos recursos genéticos marinhos, desde que isso não corresponda à inviabilidade do princípio da liberdade em alto mar.

Tal fenômeno hermenêutico justifica-se na possibilidade de a redação do art. 87, 1, que garante o princípio da liberdade no alto mar - na medida em que reconhece haver diversas espécies de liberdade, cujos exemplos, "inter alia"22, são indicados em suas alíneas -, permitir a identificação da utilização livre e gratuita dos recursos genéticos ao alto mar. A expressão inter alia desse artigo indicaria que o princípio da liberdade do alto mar pode ser aplicado em situações diferentes daquelas expressas nas alíneas, isto é, a CNUDM não teria esgotado as possibilidades de utilização livre e gratuita do alto mar. Ali, estariam listados meros exemplos, aplicando-se analogicamente o mesmo regime jurídico a todas as demais possível utilizações do alto mar.

19 Art. 87, 1,e, da CNUDM.

20 Art. 87, 1, $f$, da CNUDM.

21 Art. 87, 1, parte final, da CNUDM.

22 Art. 87, 1, da CNUDM. 
Nesse caso, o acesso aos recursos genéticos se equipararia à captura de recursos pesqueiros. Por analogia, o direito de livre e gratuita utilização por parte de todos os Estados da comunidade internacional seria garantido não somente com relação aos recursos pesqueiros, mas também aos recursos genéticos. Por conseguinte, toda a diversidade biológica do alto mar seria internacionalmente res nullius ${ }^{23}$. Com isso, todos os Estado teriam o direito de encaminhar suas embarcações ao alto mar em vista da livre realização de atividade de pesca, pesquisa científica e utilização dos recursos genéticos, sem qualquer obrigação de partilha de benefícios com outros Estados da comunidade internacional.

$\mathrm{O}$ uso da analogia, nesse caso, causa insegurança ${ }^{24}$, pois não ficam claros os limites de atuação em alto mar. No que concerne à utilização da biodiversidade marinha, essa interpretação fortalece os Estados desenvolvidos que, por serem detentores de tecnologia, tornam-se mais competitivos quando da busca dos recursos biológicos. Sendo os recursos genéticos do alto mar res nullius, os Estados, que têm maior capacidade tecnológica, apropriam-se deles com mais facilidade, concentrando em si mesmos todos os benefícios obtidos com sua utilização. Tal concentração de benefícios tende a tornar ainda mais dramáticas as desigualdades socioeconômicas internacionais, pois "o potencial de ganhos econômicos da biotecnologia modificou as pesquisas científicas de um exercício primordialmente acadêmico para um exercício industrial e empreendedor" ${ }^{25}$ (GUNERATNE, 2013, p. 28, tradução nossa).

Diante disso, as negociações em curso acerca do Acordo sobre BBNJ são uma oportunidade ímpar para os Estados em desenvolvimento de criação normativa em favor da construção de uma conjuntura internacional de mais intensa cooperação em vista da universalização do desenvolvimento socioeconômico, o que exige a partilha com todos dos benefícios obtidos por poucos.

23 Em 2016, em artigo sobre o direito internacional de proteção da biodiversidade marinha, sustentouse justamente que os recursos genéticos do alto mar seriam de livre e gratuita apropriação pelos Estados em razão do disposto no art. 87 da CNUDM (TOLEDO, 2016, p. 53).

24 É o caso, por exemplo, da liberdade de exercícios militares em alto mar. Enquanto o art. 88 da CNUDM determina que aquele espaço marítimo internacionalizado é destinado a fins pacíficos, considera-se, em geral, que esse dispositivo não proíbe testes bélicos ou manobras de marinha de guerra, apesar de o art. 301 da CNUDM proibir a realização de atividades militares contrárias à Carta das Nações Unidas (TANAKA, 2015).

25 "The potential economic gains of biotechnology have transformed scientific research from a primally academic exercise into an industrial and entrepreneurial one". 


\section{RECURSOS GENÉTICOS MARINHOS DO ALTO MAR: "RES COMMUNIS"}

Em que medida os Estados podem tratar a utilização sustentável dos recursos genéticos do alto mar diferente do que fizeram com os recursos pesqueiros? Para responder, volta-se à expressão inter alia do art. 87, 1, da CNUDM. Antes de tudo, é necessário reconhecer que, apesar de ser um princípio da CNUDM, a liberdade do alto mar não é absoluta (TANAKA, 2015). Ao contrário, nos termos do art. 87, 2, da CNUDM, tal liberdade somente pode ser exercida individualmente por um Estado respeitando os interesses e direitos de todos os demais Estados. Há, portanto, a preocupação dos Estados partes da CNUDM de não tornar o alto mar um espaço monopolístico, em razão das disparidades materiais entre os países.

Por conta disso, é possível, por meio do Acordo sobre BBNJ, que os Estados, garantindo a liberdade do alto mar, prevejam um regime jurídico de maior equilíbrio concorrencial. Com essa perspectiva, a expressão inter alia passa a ser entendida como uma abertura aos Estados de criação, por meio de tratado internacional, de obrigações diferentes em vista da utilização igualitária e universal do alto mar, cumprindo consequentemente o "princípio da igualdade de uso" (MELLO, 2001, p. 40) no alto mar.

Na medida em que a utilização dos recursos genéticos do alto mar não é identificada expressamente como liberdade de pesca, afasta-se qualquer possibilidade de analogia, instituindo um regime jurídico específico de utilização sustentável da BBNJ sem comprometer os princípios fundamentais da CNUDM. Seria, então, possível garantir o princípio da liberdade do alto mar sem que os recursos genéticos sejam res nullius?

Como prevê o art. 89 da CNUDM, o alto mar, em si mesmo, é insuscetível de reivindicação de soberania pelos Estados. Esse dispositivo convencional faz do alto mar, que, neste ponto, não se confunde com os recursos naturais do alto mar, um bem comum ou res communis (ZANELLA, 2017). De fato, por não ser possível a apropriação do alto mar por um Estado, transformando-o em território nacional, conclui-se que a integralidade do alto mar é res communis. Na medida em que os Estados não podem tornar o alto mar um espaço territorial ou um espaço de jurisdição nacional, garante-se sua internacionalização e consolida-se o direito de livre navegação.

Sendo possível a existência de res communis no alto mar como meio de circulação de embarcações, os recursos genéticos do alto mar - 
diferente dos recursos pesqueiros do alto mar, cujo regime da gratuidade de utilização é garantido na $\mathrm{CNUDM}^{26}$ - podem também ser juridicamente tratados como res communis. Basta que o Acordo sobre BBNJ determine que não apenas o alto mar, mas seus recursos genéticos sejam insuscetíveis de apropriação. Essa solução convencional teria como modelo o art. 137, 1, da CNUDM, que, tratando de outro espaço marinho internacionalizado, determina que nenhum Estado, nenhuma pessoa física ou pessoa jurídica pode apropriar-se "de qualquer parte da Área ou dos seus recursos".

Seguindo o modelo adotado para a Área na CNUDM, o Acordo sobre BBNJ deveria expressamente dispor que nenhum Estado pode reivindicar ou exercer soberania ou direitos soberanos sobre os recursos genéticos ao alto mar, assim como nenhum Estado, pessoa física ou pessoa jurídica pode apropriar-se de qualquer parte desses recursos ${ }^{27}$. Caso fosse a intenção dos Estados confirmar a natureza de res nullius dos recursos genéticos do alto mar, bastaria preverem, no Acordo sobre BBNJ, o direito à liberdade de apropriação sem obrigação de contrapartidas ${ }^{28}$.

Uma vez fixada expressamente no futuro Acordo sobre BBNJ a impossibilidade de apropriação dos recursos genéticos por Estados, pessoas físicas ou jurídicas, e consolidado seu caráter de res communis, o princípio da liberdade do alto mar permaneceria aplicável. É absolutamente conciliável esse princípio com a existência de bens comuns, como demonstra o art. 89 da CNUDM, que proíbe os Estados de pretenderem submeter qualquer parte do alto mar à sua soberania.

Sendo res communis por disposição do Acordo sobre BBNJ, mantendo-se aplicável o princípio da liberdade do alto mar, seria possível, assim, a previsão de obrigações de partilha de benefícios da utilização dos recursos genéticos do alto mar. Esses recursos seriam de livre utilização, mas não seriam mais gratuitos. Ao contrário, os Estados bioprospectores passariam a ser obrigados a compensar os demais Estados pela utilização de um bem comum, dando perspectivas materiais de desenvolvimento aos demais Estados. De fato, tendo como referência o art. 137, 2, da CNUDM, o Acordo sobre BBNJ deveria determinar que os Estados, que utilizam

26 Consideram-se gratuitos os recursos pesqueiros do alto mar, pois o art. 87, 1,e, combinado com os arts. 116-120 da CNUDM não prevê nenhum tipo de contrapartida pelo livre acesso a tais recursos biológicos. Porém, nada no texto da CNUDM impede que tais contrapartidas possam ser instituídas por acordos de pesca. Nesse caso, aquilo que é res nullius passa a ser res communis.

27 Art. 9, 3, de Revised draft text of an agreement under the United Nations Convention on the Law of the Sea on the conservation and sustainable use of marine biological diversity of areas beyond national jurisdiction.

28 Como visto, é justamente isso que se prevê na CNUDM com relação à utilização dos recursos pesqueiros do alto mar. 
recursos genéticos do alto mar, fossem obrigados a partilhar os benefícios - em especial a biotecnologia - com toda a comunidade internacional.

Apesar de ter como referência o disposto no art. 137 da CNUDM, o Acordo sobre BBNJ não pode revogar o princípio da liberdade do alto mar, em razão do mencionado art. 311, 3, da CNUDM. Por esse motivo, entende-se ser vedada aos Estados a adoção para os recursos genéticos do alto mar do regime do patrimônio comum da humanidade ou res communis humanitatis, pois, no direito do mar, tal regime presume o controle e gestão centralizados em entidade quase-soberana, que exerce um poder de "superveniência" (BEIRÃO, 2018), como é o caso da Autoridade Internacional dos Fundos Marinhos (doravante "Autoridade") em relação aos recursos da Área ${ }^{29}$.

Não sendo possível transformar os recursos genéticos do alto mar em patrimônio comum da humanidade por meio do Acordo sobre BBNJ, sem comprometer um princípio fundamental da CNUDM, sustenta-se a adoção de um regime jurídico similar ao adotado na Antártida. O sistema jurídico internacional antártico é um ótimo parâmetro para o Acordo sobre BBNJ, pois, no que concerne à pesquisa científica, há a internacionalização da Antártida como um todo ${ }^{30}$, garante-se a liberdade de pesquisa científica ${ }^{31}$ por meio da cooperação internacional ${ }^{32}$ - o em que se destaca o protagonismo da Comissão para a Conservação dos Recursos Vivos Marinhos Antárticos ${ }^{33}$ (doravante "Comissão") - e fixa-se obrigação de partilha de benefícios $^{34}$. Com efeito, no sistema jurídico antártico, fundado na cooperação (FERREIRA, 2009) de todos os integrantes da comunidade por meio da Comissão, que garante o livre acesso aos recursos biológicos antárticos a cada um dos Estados, mas fixa contrapartidas ambientais e científicas em prol de todos (FRANCO; TOLEDO, 2018). A partilha de benefícios do aproveitamento dos recursos biológicos antárticos é um importante objetivo do sistema jurídico antártico, que pode se dar especialmente por meio da transferência de tecnologia para a pesquisa científica (PUIG-MARCÓ, 2014).

Na medida em que o futuro Acordo sobre BBNJ preveja que os recursos genéticos do alto mar sejam de livre acesso, mas objeto de partilha de

29 Art.137, 2, da CNUDM.

30 Art. IV, 2, do Tratado da Antártida.

31 Art. II do Tratado da Antártida.

32 Art. 6 do Protocolo de Madri ao Tratado da Antártica.

33 Art. IX da Convenção sobre a Conservação dos Recursos Vivos Marinhos Antárticos.

34 Art. III, 1, c, do Tratado da Antártida. 
benefícios ${ }^{35}$, isso implicaria o fortalecimento dos vínculos de cooperação internacional, cujo bom exemplo é dado pela Comissão. Uma vez que tais recursos biológicos são de livre utilização, mas não gratuitos, o Acordo sobre BBNJ necessariamente deve reforçar a obrigação de cooperação internacional.

\section{COOPERAÇÃO NO ALTO MAR: CONSERVAÇÃO, PARTILHA DE BENEFÍCIOS DA UTILIZAÇÃO DE RECURSOS GENÉTICOS MARINHOS E COMBATE À BIOPIRATARIA}

Dedicado à cooperação internacional para a conservação e gestão dos recursos vivos do alto mar, o art. 118 da CNUDM determina que:

[...] os Estados cujos nacionais aproveitem recursos vivos idênticos, ou recursos vivos diferentes situados na mesma zona, efetuarão negociações para tomar as medidas necessárias à conservação de tais recursos vivos. Devem cooperar, quando apropriado, para estabelecer organizações sub-regionais ou regionais de pesca para tal fim (BRASIL, 1990).

Caso seja definido, no Acordo sobre BBNJ, que os recursos genéticos do alto mar são res communis, o que implicaria obrigações de partilha de benefícios com a comunidade internacional, a obrigação de cooperação, prevista no art. 118 da CNUDM, torna-se condição sine qua non de acesso internacionalmente lícito.

Com base nesse dispositivo, que trata dos recursos vivos como um todo, os Estados, que têm livre acesso aos recursos genéticos marinhos do alto mar, devem agir em conjunto para garantir sua conservação. Para tanto, pode-se fazê-lo diretamente ou instituir organizações ou mecanismos de cooperação internacional. A participação em comissões internacionais de acesso a recursos biológicos do alto mar é uma maneira de cumprir a obrigação de cooperação de conservação, que deve ser sempre cumprida de boa-fé (CIJ, 2010, § 145), apesar da falta de diretrizes, na CNUDM, de verificação do cumprimento (TANAKA, 2015).

Diante da falta de diretrizes, torna-se fundamental a análise do Acordo de 1995 sobre a conservação e gestão de estoques de peixes transzonais e altamente migratórios. Esse acordo é uma importante referência para a verificação do cumprimento da obrigação de cooperação em alto mar. Por ser

35 Art. 7 de Revised draft text of an agreement under the United Nations Convention on the Law of the Sea on the conservation and sustainable use of marine biological diversity of areas beyond national jurisdiction.

Veredas do Direito, Belo Horizonte, ·v.17 ·n.39 · p.339-366 · Setembro/Dezembro de 2020 
um tratado internacional de implementação das disposições da CNUDM, assim como pretende ser o Acordo sobre BBNJ, seus dispositivos inserem-se no âmbito de validade imposto pelo sistema jurídico-marinho consolidado em Montego Bay.

Segundo o art. 8, 1, do Acordo sobre peixes transzonais e altamente migratórios, que, como o art. 118 da CNUDM, trata da cooperação internacional para a conservação e gestão dos recursos biológicos, os Estados pesqueiros, em alto mar, devem cooperar diretamente ou por meio de organizações ou mecanismos de pesca sub-regionais ou regionais adequados. Uma vez constituída a organização ou instituído o mecanismo de gestão de captura, fixando consequentemente o regime de acesso e partilha de benefícios, os Estados que utilizam os recursos biológicos do alto mar devem cumprir o dever de cooperação tornando-se um membro dessa organização ou uma parte do mecanismo institucional ${ }^{36}$.

Para garantir a efetividade do sistema de cooperação internacional, o Acordo sobre BBNJ, com base no disposto no art. 8, 4, do Acordo sobre peixes transzonais e altamente migratórios, deveria estabelecer que tão somente os Estados membros da organização constituía ou partes do mecanismo instituído, ou aqueles Estados, que aceitem cumprir as medidas de conservação e gestão dos recursos genéticos do alto mar, teriam direito de acesso a eles (HAZIN, 2018). Entre tais medidas de gestão, destacam-se aquelas dedicadas à notificação de utilização e partilha de benefícios.

$\mathrm{Na}$ medida em que os recursos genéticos marinhos do alto mar forem tratados como res communis, com a adoção do Acordo sobre BBNJ, impõe-se uma gestão internacional ou descentralizada de sua utilização e conservação, como se dá com os recursos biológicos antárticos. Por isso, torna-se urgente que cada Estado da bandeira, no exercício de seus deveres de controle de suas embarcações em alto mar $^{37}$, cumpra os regulamentos, procedimentos e práticas internacionais geralmente aceitos, inclusive as medidas de gestão e conservação fixadas pela respectiva organização ou mecanismo de cooperação.

Ademais, a obrigação de cooperação internacional, a ser inserida no Acordo sobre BBNJ, tem por finalidade o que se pretende com o Acordo sobre peixes transzonais e altamente migratórias: a conciliação dos direitos soberanos dos Estados costeiros sobre os recursos genéticos de sua zona econômica exclusiva e os direitos de liberdade de utilização sustentável dos recursos genéticos do alto mar por meio da adoção de uma abordagem

36 Art. 8, 3, do Acordo de 1995 sobre a conservação e gestão dos estoques de peixes transzonais e altamente migratórios.

37 Art. 94, 5, da CNUDM. 
integral (MOLENAAR, 2011).

Visto que um mesmo recurso genético marinho pode se encontrar naturalmente tanto na zona econômica exclusiva como em setor adjacente do alto mar, o Estado costeiro e os Estados, que utilizam tal recurso em alto mar, devem cooperar diretamente ou por intermédio de organizações ou mecanismos internacionais para tomar as medidas compatíveis para garantir a conservação e gestão do referido recurso biológico em espaço nacional e em espaço fora da jurisdição nacional.

A cooperação é fundamental, tendo em vista que os recursos genéticos do alto mar podem estar fisicamente próximos da zona econômica exclusiva, onde o Estado costeiro tem direitos soberanos de exploração, aproveitamento, conservação e gestão dos recursos naturais - inclusive genéticos - das águas sobrejacentes à plataforma continenta ${ }^{38}$. Havendo cooperação entre Estado costeiro e Estados bioprospectores, cria-se um mecanismo de cooperação que pressupõe o respeito dos direitos de todos. Na medida em que, conforme os arts. 21 e 22 do Acordo sobre peixes transzonais e altamente migratórios, por meio desse mecanismo de cooperação, instituem-se procedimentos de controle de embarcações no alto mar por Estado diferente do Estado da bandeira (MOLENAAR, 2011), surge um mecanismo novo de combate à biopirataria ${ }^{39}$ de recursos genéticos do Estado costeiro. A liberdade de utilização dos recursos genéticos do alto mar não pode comprometer os direitos soberanos dos Estados costeiros sobre os recursos genéticos encontrados naturalmente em sua zona econômica exclusiva.

Além da instituição de organização ou mecanismo internacional para a utilização sustentável de recursos genéticos marinhos encontrados em zona econômica exclusiva e setores adjacentes do alto mar, além da previsão do controle amplo em alto mar de embarcações por Estados partes de tal organização ou mecanismo de cooperação internacional, a fim de enfrentar com mais eficiência a prática da biopirataria, é necessário que o futuro Acordo sobre BBNJ também preveja a todos os Estados partes a obrigação de adotarem, no âmbito interno, a exigência de apresentação do certificado de origem dos recursos genéticos utilizados por pessoas físicas ou jurídicas.

Os Estados de destino do recurso genético marinho coletado devem exigir a apresentação do certificado de origem do material. O propósito dessa medida é obrigar que haja uma declaração expressa por parte dos 38 Art. 56, 1, a, da CNUDM.

39 Biopirataria é a transferência transfronteiriça de recursos biológicos sem o consentimento do Estado titular do direito soberano de exploração, aproveitamento, gestão e conservação (TOLEDO, 2019). 
interessados acerca do local exato de acesso dos recursos genéticos marinhos $^{40}$, a fim facilitar a identificação do Estado titular do direito soberano de exploração, a quem cabe parte dos benefícios da utilização de tais recursos genéticos.

O Estado de origem do recurso genético marinho tem direito soberano de autorizar por meio de acordo a bioprospecção realizada em mar territorial ou zona econômica exclusiva. Esses acordos são, portanto, estratégicos instrumentos pelos quais os Estados ricos em biodiversidade marinha poderiam alcançar um nível de desenvolvimento por meio da permissão de acesso às embarcações dos Estados pobres em biodiversidade marinha, mas ricos em biotecnologia, recompensando-os de maneira justa com a repartição de benefícios. "Entretanto, nem sempre tais contratos são construídos por essa base ideal, camuflando em verdade, práticas de biopirataria e apropriação indevida de conhecimentos tradicionais" (BRITO; BIZAWU, 2016, p. 2).

\section{RECURSOS GENÉTICOS MARINHOS DA ÁREA: “RES COMMUNIS HUMANITATIS"}

No que concerne à Área, outro espaço marítimo para além da jurisdição nacional, o art. 1, 1, da CNUDM estabelece que se trata do leito do mar, os fundos marinhos e seu subsolo além dos limites da plataforma continental dos Estados costeiros. Complementando essa definição, o art. 136 da CNUDM estabelece que a Área é patrimônio comum da humanidade.

Quando se fala na Área, deve-se ter em mente que esse regime jurídico-espacial tem como princípio fundamental, nos termos do art. 311, 3, combinado com o art. 311, 6, da CNUDM, o princípio do patrimônio comum da humanidade. Esse dispositivo, reforçando a vedação geral, veda, de modo específico, qualquer posterior modificação ou revogação desse princípio. Logo, os Estados, que negociam em Nova York o Acordo sobre BBNJ, devem necessariamente levar em consideração o princípio do patrimônio comum da humanidade como base de construção do regime de utilização sustentável dos recursos genéticos marinhos ali encontrados.

A internacionalização da Área é reconhecida no art. 137, 1, da CNUDM, que determina que nenhum Estado pode reivindicar ou exercer soberania ou direitos de soberania sobre qualquer parte da Área ou seus 40 Art. 10, 2, a, de Revised draft text of an agreement under the United Nations Convention on the Law of the Sea on the conservation and sustainable use of marine biological diversity of areas beyond national jurisdiction. 
recursos. Ademais, nenhum Estado, pessoa física ou pessoa jurídica pode apropriar-se de qualquer parte da Área ou de seus recursos. Em virtude dessa redação, conclui-se que não apenas a Área como um todo, mas também seus recursos seriam res communis. Porém, por força do art. 136 da CNUDM, não são eles apenas res communis, mas res communis humanitatis.

Em razão disso, na ordem jurídica marinha (FRANCKX, 2010), introduziu-se um elemento revolucionário (WOLFRUM, 1983), que é a criação da Autoridade como representante da humanidade ${ }^{41}$. Com efeito, o art. 137, 2, combinado com o art. 157, 1, da CNUDM prevê que a Autoridade é a organização por intermédio da qual os Estados Partes controlam as atividades na Área, particularmente com vista à gestão dos recursos da Área, mas que atua em nome da humanidade.

O regime jurídico da Área afasta-se significativamente daquele previsto para o alto mar. De fato, o alto mar e a Área, apesar de serem espaços fora da jurisdição nacional, têm regimes jurídicos distintos. Se o art. 89 da CNUDM diz que nenhum Estado pode se apropriar de qualquer parte do alto mar sob sua soberania sem fazer menção aos recursos; quando o art. 137, 1, diz que não somente parte da Área, mas seus recursos, não podem ser apropriados; não há dúvida de que são estatutos jurídico-espaciais próprios. Ao passo que aquele se funda no princípio da liberdade, com base no disposto no art. 87 da CNUDM, este rege-se pelo princípio do patrimônio comum da humanidade. Ambos insuscetíveis de modificação ou derrogação por força do art. 311, 3, combinado com o art. 311, 6, da CNUDM.

$\mathrm{O}$ art. 137, 2, da CNUDM estabelece que todos os direitos sobre os recursos da Área pertencem à humanidade. Isso impede que se trate a Área à luz do regime jurídico aplicado no alto mar (FITZMAURICE, 2002, p. 154). Logo, diferente do que ocorre no alto mar, a utilização unilateral da Área é simplesmente ilícita, sendo necessária a participação direta ou indireta da Autoridade, pois "[...] o uso do fundo do mar e seus recursos para o benefício da humanidade como um todo, com particular consideração pelos interesses e necessidades dos países em desenvolvimento [...]"42 (SCOVAZZI, 2007, p. 12, tradução nossa).

A participação da Autoridade é elemento básico do regime do

41 No que concerne à partilha de benefícios e à conservação ambiental, é cada vez mais evidente a necessidade do reconhecimento da personalidade jurídica internacional da humanidade (REIS; BIZAWU, 2015, p. 29-65).

42 " $[\ldots]$ the use of the seabed and its resources for the benefit of mankind as a whole with particular consideration for the interests and needs of developing countries $[\ldots]$ ". 
patrimônio comum da humanidade, na ordem jurídica marinha. Tal elemento deve ser levado em consideração pelos Estados que negociação o Acordo sobre BBNJ, quando da fixação do regime da utilização dos recursos genéticos marinhos da Área.

Quando se trata de recursos da Área, estes são, segundo o art. 133, $a$, da CNUDM, todos os recursos minerais sólidos, líquidos ou gasosos in situ, incluindo os nódulos polimetálicos. Logo, os recursos não são jamais recursos genéticos. Contudo, existem na Área não apenas recursos minerais. Sobretudo os recursos biológicos - fontes hidrotermais, fauna abissal ou hadal, bactérias - se tornam estratégicos para o setor biotecnológico internacional. A Área tem uma das mais ricas biodiversidades do planeta ${ }^{43}$, sendo suas espécies pouco conhecidas e havendo consequentemente alto o risco de dano ecossistêmico em face de uma utilização não sustentável.

No que concerne aos recursos genéticos da Área, apesar de não serem recursos, nos termos da CNUDM, não há dúvida de que são eles patrimônio comum da humanidade. Ora, mesmo inexistindo dispositivo expresso sobre os recursos genéticos da Área, visto que os arts. 136 e 137, 1, da CNUDM determinam que, além dos recursos minerais, a Área como um todo é patrimônio comum da humanidade, é imperativa a conclusão de que há algo na Área que, não sendo recurso mineral, não deixa de ser res communis humanitatis. Portanto, não se sustenta a afirmação, como já se fez antes ${ }^{44}$, de que o regime jurídico do alto mar é aplicável para a utilização sustentável dos recursos genéticos da Área. Nesse sentido, parte da doutrina sustenta que, em vista da ausência de dispositivo expresso na CNUDM, dever-se tratar esses recursos como se tratam os recursos genéticos do alto mar, isto é, como res nullius (BEURIER, 2014b). Ao contrário, justamente por ser a Área como um todo patrimônio comum da humanidade, os recursos genéticos ali encontrados naturalmente jamais poderiam ser tratados como res nullius.

Assim, na Área, desde 1994 - quando entrou em vigor a CNUDM - os Estados não têm liberdade de encaminhar seus nacionais e embarcações à Área, a fim de coletar recursos genéticos marinhos, sem o consentimento prévio da Autoridade e sem garantir contrapartidas à humanidade, tendo em vista que tais recursos já são res communis humanitatis.

43 Vide exempli gratia Grassle (1991).

44 Toledo (2016). 


\section{GESTÃO DOS RECURSOS GENÉTICOS MARINHOS DA ÁREA PELA AUTORIDADE INTERNACIONAL DOS FUNDOS MARINHOS}

Sendo patrimônio comum da humanidade, a Autoridade teria competência para autorizar, controlar a utilização dos os recursos genéticos da Área, exigindo a partilha de benefícios em nome da humanidade? O mandato da Autoridade é mais amplo do que se imagina à primeira vista.

Em razão do disposto no art. 145, $b$, da CNUDM, cabe à Autoridade adotar normas, regulamentos e procedimentos apropriados para proteger e conservar os recursos naturais - o que inclui os recursos genéticos - da Área, prevenindo danos à flora e à fauna do meio marinho (ARMAS-PFIRTER, 2018). Diante disso, percebe-se que a Autoridade não apenas trata de recursos minerais, mas também tem competência para adotar medidas de conservação dos recursos genéticos.

No que concerne, por sua vez, à pesquisa científica na Área, esta deve ser realizada para o benefício da humanidade como um todo ${ }^{45}$. Uma vez que essa atividade investigativa pode envolver a coleta de componentes da biodiversidade, inclusive de material genético (GLOWKA, 1996), trata-se dimensão importante da utilização dos recursos genéticos da Área da qual participa diretamente a Autoridade. Realmente, o art. 143, 2, da CNUDM estabelece ser competência da Autoridade a promoção e o impulso à realização da investigação científica marinha na Área, coordenando e difundindo os resultados da pesquisa realizada.

Os Estados podem realizar pesquisa científica marinha na Área, desde que seus programas sejam elaborados por intermédio da Autoridade ou outras organizações internacionais, incentivando assim a cooperação internacional com outros países e com a Autoridade e garantindo a partilha de benefícios com Estados em desenvolvimento ou tecnologicamente desfavorecidos ${ }^{46}$.

Verifica-se, portanto, que a CNUDM já assegura à Autoridade o protagonismo na conservação e na pesquisa científica com recursos genéticos marinhos na Área. Soma-se a isso o fato de tais recursos serem patrimônio comum da humanidade. Por isso, defende-se que o Acordo sobre BBNJ simplesmente reafirme isso expressamente e preveja a competência da Autoridade para, não apenas atuar para a conservação e pesquisa científica 
dos recursos genéticos da Área, mas especialmente realizar a gestão da utilização sustentável dos recursos genéticos. Desde que isso seja reconhecido, tornar-se-á necessário o consentimento da Autoridade para a exploração e aproveitamento desses recursos, o que se dá por meio de contrato pelo qual haja a obrigação de partilha dos benefícios obtidos com toda a humanidade, especialmente com os países subdesenvolvidos.

\section{CONCLUSÃO}

A partir da adoção, em 2017, da Resolução 72/249, a Assembleia Geral das Nações Unidas convocou uma conferência para a celebração de um Acordo de implementação da CNUDM no que concerne à conservação e utilização sustentável de BBNJ. Com base no esboço de Acordo elaborado pela organização internacional em 2019, após a realização de três sessões de negociação; tendo como parâmetro o disposto no Acordo sobre peixes transzonais e altamente migratórios e no sistema jurídico internacional antártico; com o intuito de contribuir para o debate doutrinário sobre o Acordo que deverá ser adotado a partir de 2021; conclui-se o seguinte.

A expressão diversidade biológica inserida no termo BBNJ refere-se aos recursos genéticos marinhos, excluindo-se da pauta de negociação nas Nações Unidas qualquer dispositivo sobre pesca, tendo em vista a vigência de importantes instrumentos sobre o tema como, por exemplo, o Acordo sobre peixes transzonais e altamente migratórios.

Sob a égide da CNUDM, espaços marítimos para além da jurisdição nacional são tão somente o alto mar e a Área ${ }^{47}$, que, apesar de serem ambos espaços internacionalizados ${ }^{48}$, têm regimes jurídicos distintos. Enquanto na Área vige o princípio do patrimônio comum da humanidade, no alto mar prevalece o princípio da liberdade.

Em conformidade com o art. 311, 3, combinado com o art. 311, 6, ambos da CNUDM, o Acordo sobre BBNJ, em negociação, não pode afetar os princípios fundamentais nela enunciados. Acerca dos espaços marítimos internacionalizados, são princípios fundamentais o princípio da liberdade

47 Art. 137, 1, da CNUDM.

48 Como visto, apesar de o alto mar ser res communis, cujas implicações em favor da comunidade internacional são evidentes, não se pode considerá-lo res communis humanitatis, tendo em vista o caráter específico desse regime jurídico-espacial, no âmbito do direito do mar. A identificação do alto mar como espécie de patrimônio comum da humanidade encontra-se na tese Les grands enjeux contemporains du droit international des espaces maritimes et fluviaux et du droit de l'environnement: de la conservation de la nature à la lutte contre la biopiraterie, defendida em 2012, na Université Panthéon-Assas Paris 2, por André de Paiva Toledo, mas não se encontra em suas obras mais recentes. 
no alto mar e o princípio do patrimônio comum da humanidade na Área.

Segundo os arts. 87 e 89 da CNUDM, nenhum Estado pode pretender submeter qualquer parte do alto mar à sua soberania, sem se referir à apropriação de seus recursos naturais. Diante disso, face à liberdade de pesca em alto mar sem obrigações de partilha de benefícios com a comunidade internacional, conclui-se que o alto mar é res communis, ao passo que seus recursos - inclusive genéticos - seriam res nullius, isto é, de livre e gratuita apropriação pelos nacionais dos Estados da bandeira.

Contudo, a expressão inter alia, inserida no art. 87, 1, da CNUDM, dá margem para que outras liberdades em alto mar sejam expressamente determinadas por tratado posterior, o que significa também que outras utilizações legítimas do mar, como a utilização de recursos genéticos, possam ter tratamento diferente do disposto naquele artigo. Em razão dessa abertura, tendo como parâmetro o direito internacional antártico, o Acordo sobre BBNJ deveria estabelecer que nenhum Estado, pessoa física ou pessoa jurídica poderia se apropriar dos recursos genéticos do alto mar sem garantir a partilha de benefícios com a comunidade internacional, tornando-os, portanto, res communis. Assim, como na Antártida, garante-se a descentralização do controle do acesso aos recursos genéticos do alto mar, em harmonia com o princípio da liberdade, mas impõem-se aos Estados da bandeira contrapartidas em prol da comunidade internacional.

Em razão do art. 118 da CNUDM sobre a cooperação internacional de gestão e conservação dos recursos biológicos do alto mar - inclusive genéticos -, em consonância com o irrevogável princípio da liberdade do alto mar, os Estados devem se organizar institucionalmente para regulamentar o acesso aos recursos genéticos do alto mar por parte de seus nacionais. Tendo como referência o art. 8, 4, do Acordo sobre peixes transzonais e altamente migratórios, o Acordo sobre BBNJ deveria prever que somente terão acesso aos recursos genéticos do alto mar os Estados partes ou aqueles comprometidos em seguir o regulamento internacional, garantindo assim a partilha de benefícios com a comunidade internacional.

No âmbito de tal cooperação internacional de gestão e conservação dos recursos genéticos do alto mar, o Acordo sobre BBNJ deveria estabelecer a obrigação de todos os Estados de comprovar internamente a origem dos recursos genéticos marinhos utilizados por seus nacionais como condição para seu aproveitamento. Esse controle no Estado de destino dos recursos genéticos possibilita mais eficiência no combate à biopirataria, garantindo a partilha de benefícios com os Estados de origem dos recursos genéticos ou com a comunidade internacional. 
Segundo o art. 137, 1, da CNUDM, nenhum Estado pode reivindicar ou exercer soberania ou direitos de soberania sobre qualquer parte da Área ou seus recursos. O mesmo dispositivo convencional determina que nenhum Estado, pessoa física ou pessoa jurídica pode apropriar-se de qualquer parte da Área ou de seus recursos. Conclui-se assim que, diferente do alto mar, seriam res communis tanto a Área quanto seus recursos. Entretanto, por força do art. 136, a Área e seus recursos não são apenas res communis, mas res communis humanitatis. Não sendo os recursos genéticos "recursos", nos termos do art. 133 da CNUDM, são eles componentes da biodiversidade da Área, que é patrimônio comum da humanidade.

De acordo com o art. 145, $b$, combinado com o art. 143, 3, ambos da CNUDM, a Autoridade é competente para regulamentar a conservação dos recursos genéticos da Área, assim como para elaborar os programas de pesquisa científica, garantindo a partilha de benefícios com a comunidade internacional. Diante disso, o Acordo sobre BBNJ deveria expressamente reconhecer a competência da Autoridade para a gestão dos recursos genéticos da Área.

\section{REFERÊNCIAS}

ADEDE, A. O. The Treaty System from Stockholm (1972) to Rio de Janeiro. Pace Environmental Law Review, v. 13, n. 1, p. 33-48, 1995.

ARMAS-PFIRTER, F. M. The International Seabed Authority and the Protection of Biodiversity. In: TOLEDO, A. P.; TASSIN, V. J. M. Guia de navegação da biodiversidade marinha para além da jurisdição nacional. Belo Horizonte: D’Plácido, 2018. p. 221-246.

BEIRÃO, A. P. O braço estatal sobre o leito do mar. In: TOLEDO, André de Paiva; TASSIN, V. J. M. Guia de navegação da biodiversidade marinha para além da jurisdição nacional. Belo Horizonte: D’Plácido, 2018. p. 99-130.

BEURIER, J.-P. Émergence du régionalisme. In: BEURIER, J.-P. Droits maritimes. 3. ed. Paris: Dalloz, 2014a. p. 1316-1328.

BEURIER, J.-P. Limitation de la pêche en haute mer par la conservation de la ressource. In: BEURIER, J.-P. Droits maritimes. 3. ed. Paris: Dalloz, 2014b. p. $1345-1351$.

BEURIER, J.-P. Océan, espace à polyrégimes. In: BEURIER, J.-P. (éd.). 
Droits maritimes. $3^{e}$ éd. Paris: Dalloz, 2014c. p. 74-83.

BRASIL. Câmara dos Deputados. Decreto n. 99.165, de 12 de março de 1990. Promulga a Convenção das Nações Unidas sobre o Direito do Mar. Diário Oficial da União: seção 1, Brasília, DF, p. 5169,14 mar. 1990. Disponível em: https://www2.camara.leg.br/legin/fed/decret/1990/decreto-99165-12-marco-1990-328535-publicacaooriginal-1-pe.html. Acesso em: 10 set. 1990 .

BRITO, N. B. V.; BIZAWU, S. K. Contratos de bioprospecção e propriedade intelectual: uma análise das medidas alternativas no sistema de patentes para otimizar a proteção da biodiversidade. Revista de Direito, Inovação, Propriedade Intelectual e Concorrência, v. 2, n. 1, p. 1-21, 2016.

CHURCHILL, R. R.; LOWE, A. V. Law of the Sea. 3. ed. Manchester: Manchester University Press, 1999.

CIJ - COUR INTERNATIONALE DE JUSTICE. Usines de pâte à papier sur le fleuve Uruguay (Argentine c. Uruguay), arrêt. C.I.J. Recueil, 2010. p. 14.

DAILLIER, P.; FORTEAU, M.; PELLET, A. Droit international public. 8. ed. Paris: L.G.D.J., 2009. p. 61.

FERREIRA, F. R. G. O sistema do Tratado da Antártida: evolução do regime e seu impacto na política externa brasileira. Brasília, DF: Fundação Alexandre de Gusmão, 2009.

FITZMAURICE, M. A. International protection of the environment. Boston: Martinius Nijhoff, 2002.

FRANCKX, E. The international seabed authority and the common heritage of mankind: the need for states to establish the outer limits of their continental shelf. The International Journal of Marine and Coastal Law, v. 25, p. $543-567,2010$.

FRANCO, A. C.; TOLEDO, A. P. O sistema jurídico internacional antártico sobre a conservação das baleias: do Tratado da Antártida ao Caso "Caça à baleia na Antártida". In: BORGES, T. C.; ZANELLA, T. V.; SUBTIL, L. C. Direito do mar: reflexões, tendências e perspectivas. v. 2. Belo Horizonte: D'Plácido, 2018. p. 9-42.

GLOWKA, L. The deepest of ironies: genetic resources, marine scientific research, and the area. Ocean Yearbook Online, v. 12, n. 1, p. 154-178, 
1996.

GRASSLE, J. F. Deep-sea benthic biodiversity. Bioscience, v. 41, p. 464469, 1991.

GUNERATNE, C. Genetic resources, equity and International Law. Cheltenham: Edward Elgar, 2013.

HAZIN, F. H. V. Recursos pesqueiros e o novo acordo internacional para a conservação e o uso sustentável de biodiversidade em áreas além da jurisdição nacional. In: TOLEDO, A. P.; TASSIN, V. J.M. Guia de navegação da biodiversidade marinha para além da jurisdição nacional. Belo Horizonte: D’Plácido, 2018. p. 371-392.

LE HARDY, M. Que reste-t-il de la liberté de la pêche en haute mer? Essai sur le regime juridique de l'exploitation des ressources biologiques de la haute mer. Paris: Pedone, 2002.

LEARY, D. Agreeing to disagree on what we have or have not agreed on: the current state of play of the BBNJ negotiations on the status of marine genetic resources in areas beyond national jurisdiction. Marine Policy, v. 99, p. 21-29, 2019.

LEARY, D. et al. Marine genetic resources: a review of scientific and commercial interest. Marine Policy, v. 33, p. 183-194, 2009.

LEVY, J.-P. La conférence des Nations unies sur le droit de la mer, histoire d'une négociation singulière. Paris: Pedone, 1980.

LOSURDO, D. Guerra e revolução: o mundo um século após outubro de 1917. São Paulo: Boitempo, 2017.

MELLO, C. D.A. Alto-mar. Rio de Janeiro: Renovar, 2001.

MOLENAAR, E. J. Non-Participation in the Fish Stocks Agreement: status and reasons. The International Journal of Marine and Coastal Law, v. 26, 2011, p. 195-234.

O'REGAN, C. The Universal Declaration of Human Rights at 70: A time to look back, and a time to look forward. Journal of the British Academy, n. 6, p. 259-279, 2018.

PUIG-MARCÓ, R. Access and benefit sharing of Antarctica's biological material. Genomics, v. 17, p. 1-6, 2014. 
REIS, É. V. B.; BIZAWU, K. Encíclica Laudato Si à luz do direito internacional do meio ambiente. Veredas do Direito, Belo Horizonte, v. 12, n. 23, p. 29-65, 2015.

SCOVAZZI, T. The concept of common heritage of mankind and the genetic resources of the seabed beyond the limits of national jurisdiction. Agenda Internacional, n. 25, p. 11-24, 2007.

SOARES, G. F. S. Direito Internacional do Meio Ambiente: emergência, obrigações e responsabilidades. São Paulo: Atlas, 2001.

TANAKA, Y. The International Law of the Sea. 2. ed. Cambridge: Cambridge University Press, 2015. (e-book)

TOLEDO, A. P. Direito Internacional e biopirataria. Belo Horizonte: D’Plácido, 2019.

TOLEDO, A. P. La protection juridique internationale de la biodiversité marine. Veredas do Direito, Belo Horizonte, v. 13, n. 27, p. 31-62, 2016.

TYAGI, Y. Permanent sovereignty over natural resources. Cambridge Journal of International and Comparativa Law, v. 4, n. 3, p. 588-615, 2015.

UNITED NATIONS. Revised draft text of an agreement under the United Nations Convention on the Law of the Sea on the conservation and sustainable use of marine biological diversity of areas beyond national jurisdiction. 27 nov. 2019. Disponível em https://www.un.org/bbnj/sites/www. un.org.bbnj/files/revised_draft_text_a.conf_.232.2020.11_advance_unedited_version.pdf. Acesso em: 10 set. 2020.

WOLFRUM, R. The principle of the common heritage of mankind. Zeitschrift für ausländisches öffentliches Recht und Völkerrecht, v. 43, p. 312337, 1983.

YANAI, S. Rule of Law over the Seas and Oceans. United Nations Convention on the Law of the Sea at 30. Yeosu, Republic of Korea, 12 August 2012. Disponível em: https://www.itlos.org/fileadmin/itlos/documents/ statements_of_president/yanai/Yeosu_Korea_UNCLOS_at_30_11-13_ Aug_2012_2_.pdf. Acesso em: 10 set. 2020.

ZANELLA, T. V. Manual de Direito do Mar. Belo Horizonte: D’Plácido, 2017. 
Artigo recebido em: 25/09/2020. Artigo aceito em: 16/12/2020.

\section{Como citar este artigo (ABNT):}

TOLEDO, A. P.; BIZAWU, K. Acordo sobre Biodiversidade Marinha para Além da Jurisdição Nacional (BBNJ): regime jurídico internacional de utilização sustentável dos recursos genéticos marinhos do alto mar e da área. Veredas do Direito, Belo Horizonte, v. 17, n. 39, p. XXX-XXX, set./dez. 2020. Disponível em: http://www.domhelder.edu.br/revista/index.php/veredas/article/view/1968. Acesso em: dia mês. ano. 